Research Article

\title{
Experimental Investigation on Shock Mechanical Properties of Red Sandstone under Preloaded 3D Static Stresses
}

\author{
Niu Yong ${ }^{1}$, Li Kegang ${ }^{1}$, Liu Deke ${ }^{1}$, Li Xianglong ${ }^{1}$ and Peng Shoujian ${ }^{2}$ \\ ${ }^{I}$ Faculty of Land Resource Engineering, Kunming University of Science and Technology, Kunming 650093, China \\ ${ }^{2}$ School of Engineering, The University of Queensland, Qld 4072, Australia
}

Received 9 June 2015; Accepted 29 November 2015

\begin{abstract}
Triaxial impact mechanical performance experiment was performed to study the mechanical properties of red sandstone subjected to three-dimensional (3D) coupled static and dynamic loads, i.e., three confining pressures $(0,5$, and $10 \mathrm{MPa})$ and three axial pressures $(11,27$, and $43 \mathrm{MPa})$. A modified 3D split Hopkinson pressure bar testing system was used. The change trend in the deformation of red sandstone and the strength and failure modes under axial pressures and confining pressures were analyzed. Results show that, when the confining pressure is constant, the compressive strength, secant modulus, and energy absorbed per unit volume of red sandstone initially increases and subsequently decreases, whereas the average strain rate exhibits an opposite trend. When the axial pressure is constant, both the compressive strength and secant modulus of red sandstone are enhanced, but the average strain rate is decreased with increasing confining pressure. The energy absorbed per unit volume is initially increased and subsequently decreased as the confining pressure increases. Red sandstone exhibits a cone-shaped compression-shear failure mode under the 3D coupled static and dynamic loads. The conclusions serve as theoretical basis on the mechanical properties of deep medium-strength rock under a high ground stress and external load disturbance condition.
\end{abstract}

Keywords: Rock mechanics, Shock mechanical properties, 3D coupled static and dynamic loads, Strain rate, Failure mode

\section{Introduction}

With the rapid economic development, the increase in the demand for energy has been growing in recent years. Shallow resources have nearly been exhausted; thus, exploitation of deep resources is imperative. Many studies have indicated that deep rocks exhibit a significantly different rock mechanism from traditional rock statics and dynamics. Deep rocks are subject higher static loads, like in situ stress, tectonic stress, and dead weight, before dynamic loading, like blasting vibration, earthquake, and drilling. For example, deep mining, Fig.1 [1] shows the stress conditions of deep rocks under high ground stress and dynamic loads. Points A and B in Fig.1(a), which represent pillar and deep rocks affected by a combination of static stress and dynamic load, are under one-dimensional (1D) and three-dimensional (3D) loading conditions, respectively. The simplified simulation models of the stress states of points A and B are shown in Fig.1 (b) and Fig.1 (c), respectively.

Many studies have examined about the mechanical properties of rocks under static and dynamic loads. Demirdag et al. [2] studied the dynamic mechanical behavior of limestone and analyzed the influences of rock's physical properties on such dynamic mechanical behavior with a split Hopkinson pressure bar (SHPB) testing system. Bailly et al. [3] used an SHPB to perform a triaxial compression test to analyze the mechanical behavior of energetic material at different stress and strain rates. Zhang and Zhao [4] studied

* E-mail address: niuyonglzrr@163.com ISSN: 1791-2377 @ 2015 Kavala Institute of Technology. All rights reserved. the effects of strain rate on marble and the mesoscopic mechanism of instability with a hydraulic testing machine and an improved Hopkinson bar. Li et al. [1,5] and Zhou et al. [6] studied with a modified SHPB the mechanical properties of rocks under high-strain-rate loading within the scope of a 1D movement combination. In their studies, the strength characteristics, deformation rule, and energy patterns of the rocks were analyzed, and a constitutive model and failure model of rocks were established. They concluded that the axial pressure in front of the rock static strength is $70 \%$, the impact of rock compressive strength is higher than the pure dynamic load and static load stress, and static load is constant with increasing dynamic load. These results have reference value for $1 \mathrm{D}$ movement combination of engineering structures for loading mechanics analysis. Ye [7,8] used a dynamic and static combination loading SHPB experimental system and performed an impact test after static pressure loading on sandstone to analyze the mechanical behavior of deep underground surrounding rock subjected to dynamic disturbance after excavation unloading and the failure mode of the rock under different static pressure.

The studies on the mechanical properties of rocks have obtained some results under $3 \mathrm{D}$ coupled static-dynamic loading concerning high hydrostatic pressure and dynamic disturbance. Yin et al. [9], who used a modified load combination SHPB test system, studied the destruction of sandstone in advance by $3 \mathrm{D}$ loading and confining pressure unloading dynamic and static combination. Most engineering rock masses are subjected to bad blasting operation during blasting excavation $[10,11]$, the form dynamic load on the surrounding rock is cycle impact load. 
Jin et al. [12] examined the effects of confining pressure and axial compression on the dynamic fatigue mechanical properties of sandstone by performing a cycle impact load test on sandstone under different axial pressure and confining pressure with the use of a dynamic and static load combination test device. Gong et al. [13] used a modified 3D Hopkinson loading test device to analyze the mechanical properties of rock under $3 \mathrm{D}$ movement combination at a different strain rates.

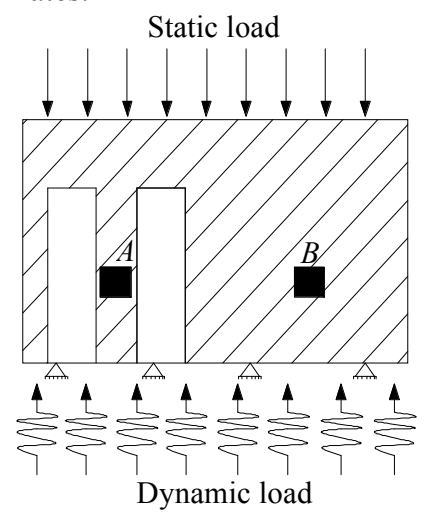

(a)

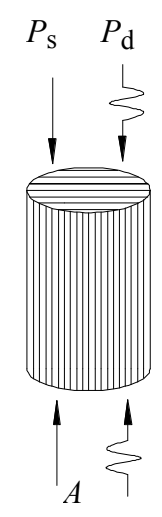

(b)

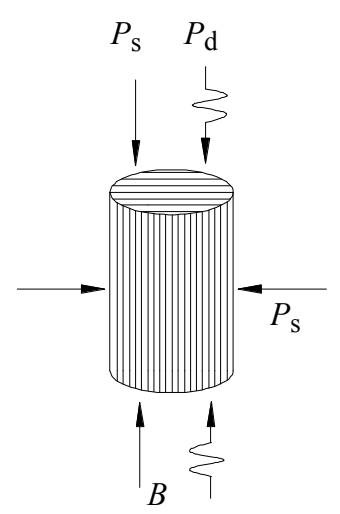

(c)
Fig.1 Sketch of stress modes of deep rock [1]. (a) Sketch map of deeplevel mining projects. (b) One-dimensional coupled static and dynamic loads. (c) Three-dimensional coupled static and dynamic loads. $P_{\mathrm{S}}$ Static load. $P_{\mathrm{d}}-$ Dynamic load

Currently, the local and foreign scholars in China have reported numerous achievements in the research of the mechanical properties of rock under coupled static and dynamic loads. By contrast, research on the mechanical properties of rocks under three-dimensional coupled static and dynamic loads need further exploration. Deep rock mechanics, including rock burst, deep shaft rock burst, zonal disintegration of rock, and rock brittle extension conversion cannot be explained by shallow rock mechanics [14]. Studying the properties of rock under 3D coupled static and dynamic loads could explain such mechanics better and provide helpful information for the prevention of dynamic disasters. Therefore, in this study, an experimental study on the mechanical properties of red sandstone is conducted using a modified SHPB test system. Mechanical experiments on the pre-impact of three-dimensional static pressure are performed, and the mechanical properties of rock under different $3 \mathrm{D}$ static pressures are analyzed to provide a theoretical basis for the study of the dynamic behavior of rock mass in deep underground engineering.

\section{Materials and methods}

\subsection{Red sandstone sample preparation}

Test samples were obtained from the red sandstone under study to investigate the deep integrity and uniformity of the underground. Each sample was cylinder in shape with a diameter of $50 \mathrm{~mm}$ and a length of $25 \mathrm{~mm}$. Each sample was carefully polished on an automatic double end face millstone machine to ensure that non-parallelism and nonperpendicularity were less than $0.02 \mathrm{~mm}$, the surface of the specimen was smooth and had no obvious defects. The physical and mechanical parameters of the sandstone under static load are shown in Table 1.

\subsection{Loading test system}

The test was conducted in Central South University, which has its own three-dimensional coupled dynamic and static loading system based on the SHPB device. Fig.2 shows the schematic diagram of the test system. An axial pressure device and confining pressure device were used to load axial static pressure and confining pressure on the rock sample, respectively, to subject the rock samples to $3 \mathrm{D}$ static condition. The lumen of a special-shaped punch is simulated to realize the $3 \mathrm{D}$ movement of the load combination of rock samples. Loading test results are handled with a data processing unit. The launch cavity adopted an "alien" punch to eliminate the dispersion effect and wave oscillation during the stress wave propagation, thereby generating a stable half sine wave to achieve the purpose of constant strain rate loading $[1,15]$. Although the actual dynamic load on an engineering rock body during blasting excavation is not stress-loading half sine wave, the dynamic mechanical properties of the surrounding engineering rock mass are not affected in the process of blasting excavation of the available half sine loading stress wave simulation study $[1,16]$. The diameter of the sample is $50 \mathrm{~mm}$; thus, a transmission lever and a club entrance with an equal diameter of $50 \mathrm{~mm}$ are used in the impact load tests.

\subsection{Test method and results}

Three-dimensional coupled dynamic and static impact tests were performed on the red sandstone samples. The axial static pressures considered for the tests were 11,27 , and 43 $\mathrm{MPa}$, which are equivalent to $20 \%, 50 \%$, and $80 \%$ of the static strength, respectively. Confining pressures selected were 0,5 , and $10 \mathrm{MPa}$. During the tests, both ends of each sample were coated with butter before placing the sample onto the testing system so as to fully expose both ends to the bar. The confining pressure was initially manually loaded before loading the axial pressure. After performing a series of experiments adopting the same settings, representative test results, which are shown in Table 2, were selected and analyzed.

\section{Result Analysis}

3.1 Analysis of deformation characteristics under 3D coupled static and dynamic loads

Figure 3 shows the stress-strain curves of red sandstone. The stress-strain curves of the rock under static and dynamic loads are compared with the stress-strain curves of the rock under uniaxial compression. Four stages of deformation have been observed: elastic deformation stage, crack development stage, pre-rupture stage, and rupture stage. As shown in Fig. 3 (a), under an axial pressure of $27 \mathrm{MPa}$, the 
stress-strain curves of the red sandstone demonstrates consistent pattern with an increase in confining pressure. The rock peak intensity shows an increasing trend with an increase in confining pressure. As shown in Fig.3 (b), under a confining pressure of $10 \mathrm{MPa}$, the peak intensity of red sandstone shows a decreasing trend after initially increasing as the axial pressure increases.

Table. 1. Physical-mechanical parameters of red sandstone under static load

\begin{tabular}{l|l|l|l|l|l}
\hline $\begin{array}{l}\text { Density } \\
/\left(\mathbf{k g} \cdot \mathbf{m}^{-3}\right)\end{array}$ & $\begin{array}{l}\text { Loading } \\
\text { rate } \\
/\left(\mathbf{M P a} \cdot \mathbf{s}^{-1}\right)\end{array}$ & $\begin{array}{l}\text { Strain } \\
\text { rate } \\
/ \mathbf{s}^{-1}\end{array}$ & $\begin{array}{l}\text { Compressive } \\
\text { strength } \\
/ \mathbf{M P a}\end{array}$ & $\begin{array}{l}\text { Secant } \\
\text { modulus } \\
/ \mathbf{G P a}\end{array}$ & $\begin{array}{l}\text { Poission's } \\
\text { ratio }\end{array}$ \\
\hline 2410 & 0.5 & $1.0 \times 10-5$ & 51.38 & 12.26 & 0.27 \\
\hline
\end{tabular}

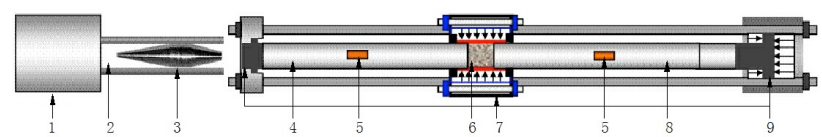

Fig.2 SHPB-based experimental system of 3D coupled static and dynamic loads.

Note: 1-gas tank; 2-pressure vessel; 3-striker; 4-incident bar; 5-strain gauge; 6-specimen; 7-confining pressure system; 8-transmission bar; 9axial compression system

Table. 2. Mechanical parameters and experimental results of the red sandstone samples under 3D coupled static and dynamic loads

\begin{tabular}{|c|c|c|c|c|c|c|c|c|}
\hline No. & $\begin{array}{l}\text { Density } \\
/ \mathrm{mm}\end{array}$ & $\begin{array}{l}\text { Length } \\
/ \mathrm{mm}\end{array}$ & $\begin{array}{l}\text { Wave } \\
\text { velocity } \\
\left(\mathrm{m} \cdot \mathbf{s}^{-1}\right)\end{array}$ & $\begin{array}{l}\text { Axial compression } \\
\text { /MPa }\end{array}$ & $\begin{array}{l}\text { Confining } \\
\text { pressure } \\
\text { /MPa }\end{array}$ & $\begin{array}{l}\text { Dynamic } \\
\text { strength } \\
\text { /MPa }\end{array}$ & $\begin{array}{l}\text { Secant } \\
\text { modulus } \\
\text { /MPa }\end{array}$ & $\begin{array}{l}\text { Strain } \\
\text { rate } \\
/ \mathrm{s}^{-1}\end{array}$ \\
\hline 9 & 48.2 & 25.32 & 3165 & 11 & 0 & 132.45 & 24.07 & 133.09 \\
\hline 75 & 48.2 & 25.37 & 3475 & 11 & 0 & 129.82 & 22.62 & 236.80 \\
\hline 76 & 48.2 & 25.35 & 3379 & 11 & 0 & 130.59 & 22.02 & 255.23 \\
\hline 30 & 48.2 & 25.47 & 3638 & 11 & 5 & 183.09 & 25.75 & 233.88 \\
\hline 35 & 48.2 & 25.42 & 3530 & 11 & 5 & 166.67 & 22.43 & 224.31 \\
\hline 62 & 48.2 & 25.36 & 3522 & 11 & 5 & 170.94 & 40.56 & 237.38 \\
\hline 46 & 48.2 & 25.33 & 3247 & 11 & 10 & 164.79 & 19.14 & 143.76 \\
\hline 47 & 48.2 & 25.37 & 3338 & 11 & 10 & 166.39 & 24.75 & 227.81 \\
\hline 49 & 48.2 & 25.35 & 3426 & 11 & 10 & 179.15 & 27.23 & 236.33 \\
\hline 16 & 48.2 & 25.32 & 3421 & 27 & 0 & 138.50 & 32.82 & 136.85 \\
\hline 26 & 48.2 & 25.41 & 3257 & 27 & 0 & 134.63 & 27.31 & 218.31 \\
\hline 77 & 48.2 & 25.41 & 3529 & 27 & 0 & 140.00 & 26.98 & 235.13 \\
\hline 36 & 48.2 & 25.42 & 3344 & 27 & 5 & 177.13 & 38.58 & 216.72 \\
\hline 37 & 48.2 & 25.48 & 3353 & 27 & 5 & 179.26 & 35.69 & 248.94 \\
\hline 64 & 48.2 & 25.38 & 3477 & 27 & 5 & 174.00 & 23.15 & 218.77 \\
\hline 51 & 48.2 & 25.36 & 3336 & 27 & 10 & 173.84 & 41.38 & 208.48 \\
\hline 52 & 48.2 & 25.36 & 3474 & 27 & 10 & 180.65 & 19.52 & 137.63 \\
\hline 55 & 48.2 & 25.34 & 3471 & 27 & 10 & 182.18 & 41.29 & 247.86 \\
\hline 22 & 48.2 & 25.40 & 3174 & 43 & 0 & 123.52 & 16.48 & 141.98 \\
\hline 24 & 48.2 & 25.35 & 3426 & 43 & 0 & 138.40 & 32.48 & 161.67 \\
\hline 81 & 48.2 & 25.38 & 3383 & 43 & 0 & 135.90 & 25.52 & 249.07 \\
\hline 41 & 48.2 & 25.37 & 3382 & 43 & 5 & 168.84 & 34.74 & 234.31 \\
\hline 43 & 48.2 & 25.40 & 3479 & 43 & 5 & 151.04 & 25.54 & 139.16 \\
\hline 74 & 48.2 & 25.37 & 3573 & 43 & 5 & 149.14 & 20.50 & 196.12 \\
\hline 57 & 48.2 & 25.35 & 3379 & 43 & 10 & 168.82 & 31.04 & 160.42 \\
\hline 58 & 48.2 & 25.36 & 3294 & 43 & 10 & 177.18 & 41.97 & 237.30 \\
\hline 59 & 48.2 & 25.33 & 3206 & 43 & 10 & 171.80 & 39.47 & 226.21 \\
\hline
\end{tabular}

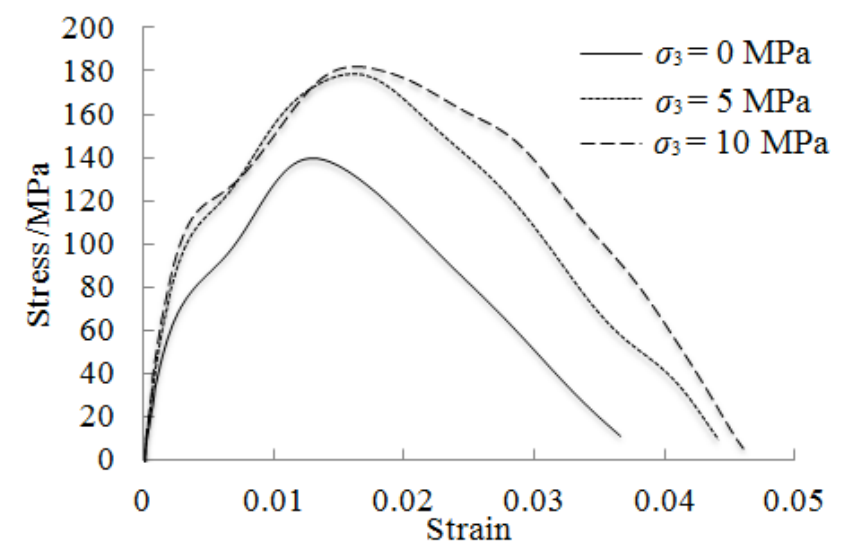

(a)

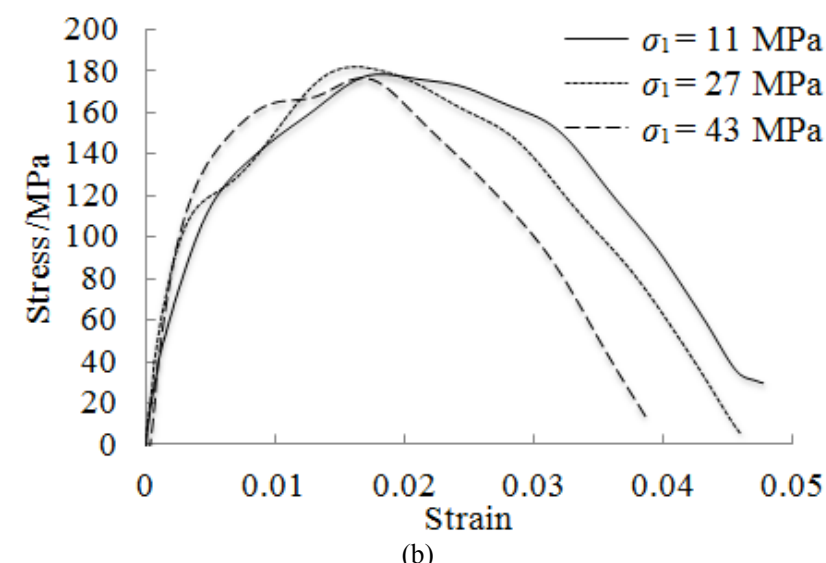

Fig.3 Stress-strain curves of red sandstone. (a) $\sigma_{1}=27 \mathrm{MPa}$. (b) $\sigma_{3}=$ $10 \mathrm{MPa} . \sigma_{1}$-Axial pressure. $\sigma_{3}$-Confining pressure

(1) Analysis of secant modulus 
Secant modulus is also used as a measure for comparison. It is defined as

$$
E_{50}=\frac{\sigma_{\mathrm{d} 50}}{\varepsilon_{\mathrm{d} 50}}
$$

where $E_{50}$ is the rock secant modulus $(\mathrm{GPa}), \sigma_{\mathrm{d} 50}$ is the dynamic compressive peak stress values at $50 \%(\mathrm{MPa})$, and $\varepsilon_{\mathrm{d} 50}$ is the corresponding axial strain value of $\sigma_{\mathrm{d} 50}$.

Figure 4 shows the relationships of the red sandstone secant modulus to confining pressure and axial pressure. As shown in Fig.4 (a), when the axial compression is constant, the secant modulus increases with confining pressure. This result implies that, when the axial compression is constant, an increase in confining pressure results in the existing pores and cracks in the rock to gradually close as the rock is compacted, suppressing the initiation and propagation of new pores and cracks and consequently causing secant modulus to increase. As shown in Fig.4 (b), when the confining pressure is constant, the secant modulus increases with axial compression after initially decreasing. Thus, when the confining pressure is constant, the rock is gradually compacted internally as the pressure in the shaft increases during the elastic deformation of the inner phase, resulting in an increase in the secant modulus. When the pressure in the shaft continues to increase, the crack development stage initiates, the rock generates new fissures as a result of excessive pressure, the rock bearing capacity weakens, and secant modulus decreases.

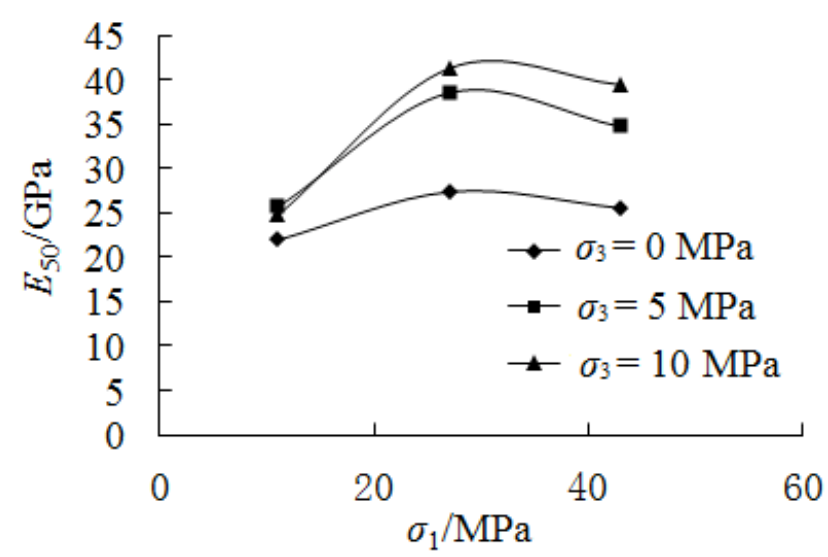

(a)

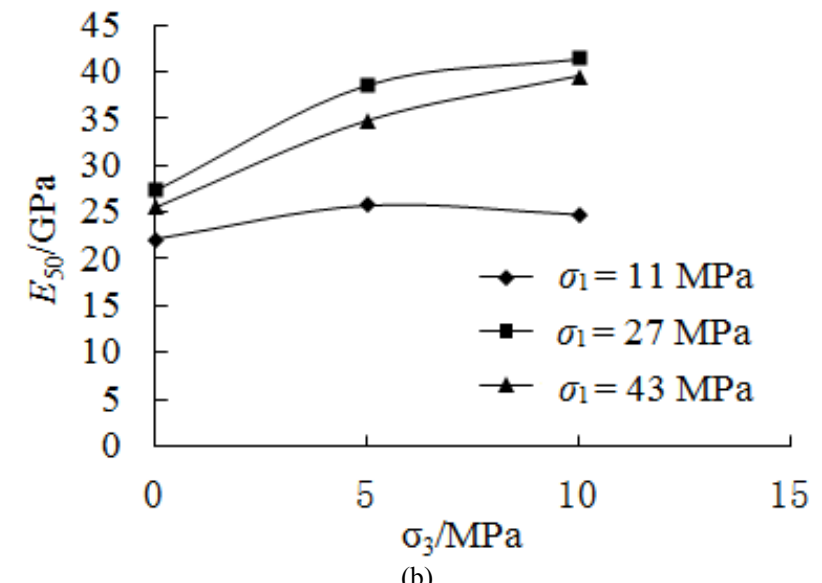

Fig.4 Variations in the secant modulus of red sandstone. (a) Variation in the secant modulus of red sandstone in relation to axial compression. (b) Variation in the secant modulus of red sandstone in relation to confining pressure

\section{(2) Analysis of strain rate}

Strain rate is the measure of the deformation rate of rocks under stress conditions. The average strain rate is a measure of the overall deformation rate characterizing rock damage. Figure 5 shows the variation in the average strain rate of red sandstone. As shown in Fig.5 (a), when the axial compression is constant, the average strain rate increases as the confining pressure decreases. This result implies that confining pressure narrows the crevice inside the rock; thus, the average strain rate decreases. As shown in Fig.5 (b), when the confining pressure is constant, the average strain rate initially decreases and subsequently increases with increasing shaft pressure. This result suggests that, in the elastic deformation of the inner phase, axial pressure reduces the internal porosity of the rock, closes the fractures in the rock rock, and decreases the average strain rate. When entering the crack development stage, the increase in axis pressure results in the expansion of the rock crack, enhanced rock deformation, increase in average strain rate.

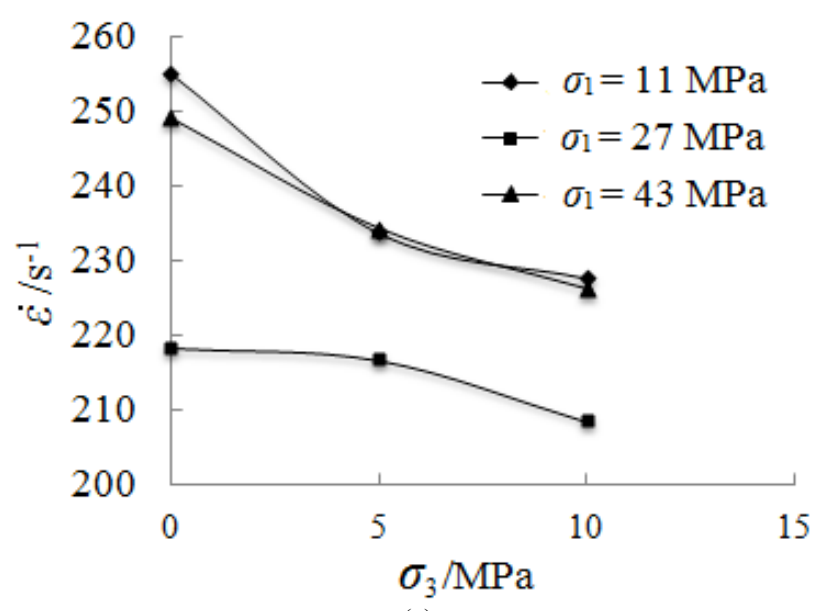

(a)

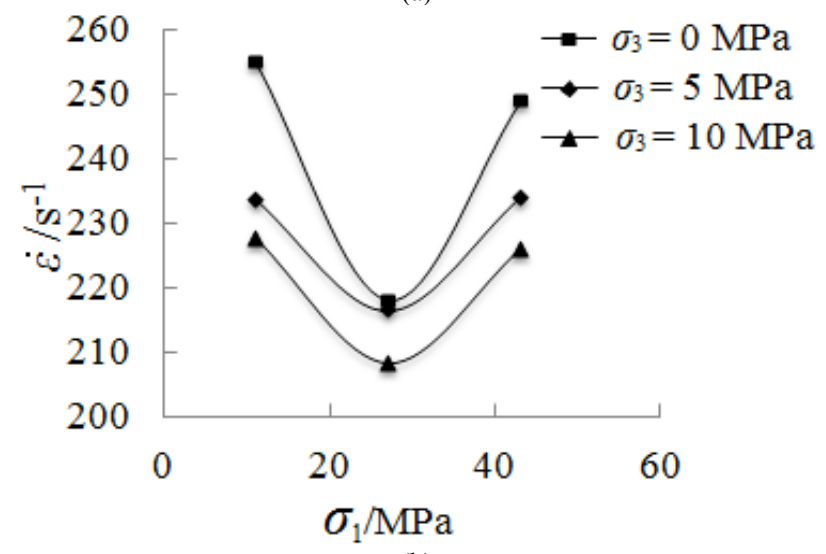

(b)

Fig.5 Variations in the strain rates of red sandstone. (a) Variation in the strain rate of red sandstone in relation to confining pressure. (b) Variation in the strain rate of red sandstone in relation to axial compression. $\dot{\varepsilon}$-Strain rate

\subsection{Analysis of strength feature under 3D coupled static and dynamic loads}

The variations in the dynamic compressive strengths of red sandstone are shown in Fig.6. Fig.6 (a) shows the variation in the compressive strength of red sandstone with respect to axial load under different confining pressures and strain rates. As the confining pressure increases, the compressive strength of red sandstone first increases and then decreases. 
Fig.6 (b) shows the variation in red sandstone with respect to confining pressure under different axial loads and strain rates. As the confining pressure increases, the compressive strength of red sandstone continuously increases. For example, when the static pressure is $43 \mathrm{MPa}$ and the confining pressures are $0 \mathrm{MPa}, 5 \mathrm{MPa}$, and $10 \mathrm{MPa}$, the compressive strengths of red sandstone are $138 \mathrm{MPa}, 149$ $\mathrm{MPa}$, and $169 \mathrm{MPa}$, respectively. The compressive strengths under confining pressures of $5 \mathrm{MPa}$ and $10 \mathrm{MPa}$ demonstrate $8 \%$ and $22 \%$ increases compared with when confining pressure is $0 \mathrm{MPa}$. This result can be ascribed to red sandstone being a sedimentary rock with pores and fissures inside. In the elastic deformation stage, the axial compression reduces the pores and fissures and thereby increases compressive strength. By contrast, when the elastic stage is surpassed, the pores become larger; thus, the compressive strength decreases. However, confining pressure can increase the density of pores and cracks inside the rock and limit the lateral deformation of rock; thus, the compressive strength increases with an increase in confining pressure. As shown in Figure 6, the red sandstone's compressive strength generally increases with increasing strain rate and exhibits a significant relationship with strain.

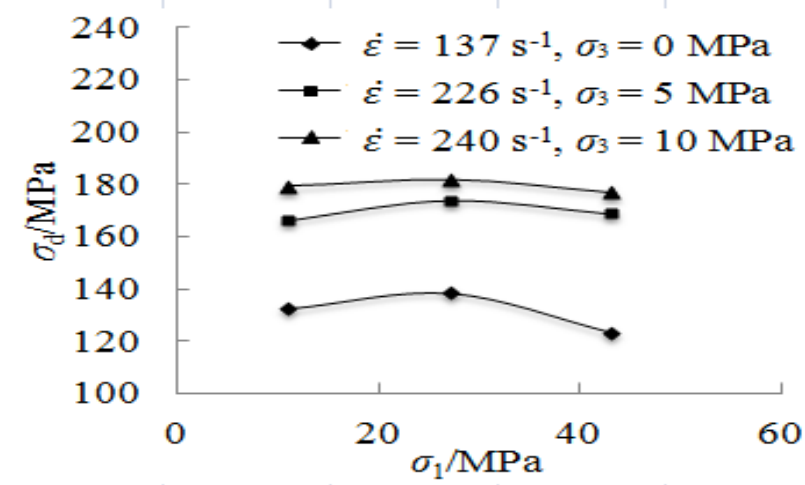

(a)

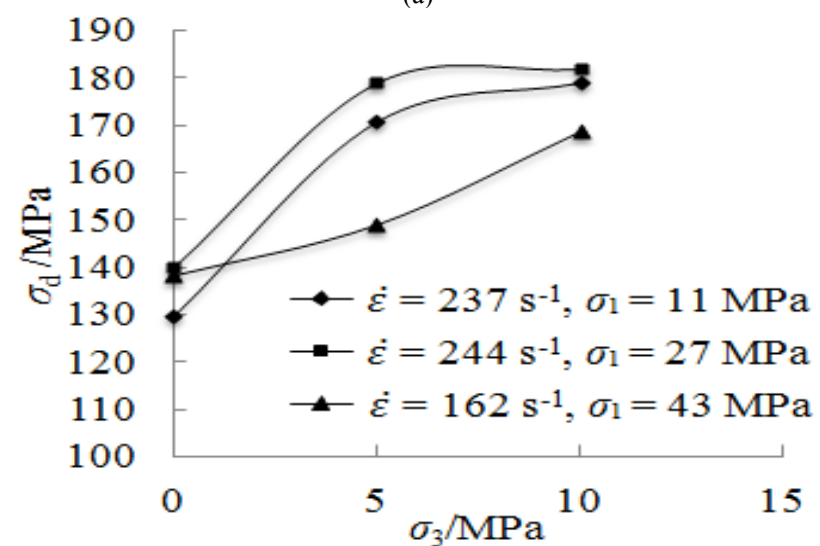

(b)

Fig.6 Variations in the compressive strengths of red sandstone. (a) Variation in the compressive strength of red sandstone in relation to axial compression. (b) Variation in the compressive strength of red sandstone in relation to confining pressure. $\sigma_{\mathrm{d}}$-Compressive strength

\subsection{Analysis of energy consumption patterns under 3D coupled static and dynamic loads}

The variations in the energy consumption patterns of the red sandstone under 3D dynamic and static loading are shown in Fig.7. Before the rock has been impacted, its own energy is insufficient to break itself under the 3D static pressure. However, after the rock has been impacted, the structure can break by absorbing energy from the outside. Fig.7 (a) shows the variation in energy absorbed per unit volume of sandstone with respect to confining pressure under different axial pressures. When the axial pressure is constant, the energy absorbed per unit volume of red sandstone initially increases and subsequently decreases with increasing of confining pressure. Thus, a larger confining pressure can close the pores inside the rock and increase the density of the rock; thus, the rock needs to absorb more energy from the outside to damage itself. When the confining pressure is considerably high, the reactive force of the lateral deformation of the rock increases under impact, the limit for the initiation and propagation of cracks in the rock is higher, and the energy absorbed from the outside for the propagation absorbed of cracks in the rock from outside decreases. Fig.7 (b) shows the variation in the energy absorbed per unit volume of red sandstone with respect to axial compression under different confining pressures. When the confining pressure is constant, the energy absorbed per unit volume of red sandstone initially increases and subsequently decreases with increasing of axial load. In the elastic deformation stage, the axial compression reduces the pores and fissures; thus, the red sandstone needs to absorb more energy from the outside to break itself. In the crack development stage, the significantly high axial load leads to the propagation of cracks inside the rock, enhanced volumetric energy release, and decrease in energy absorbed.

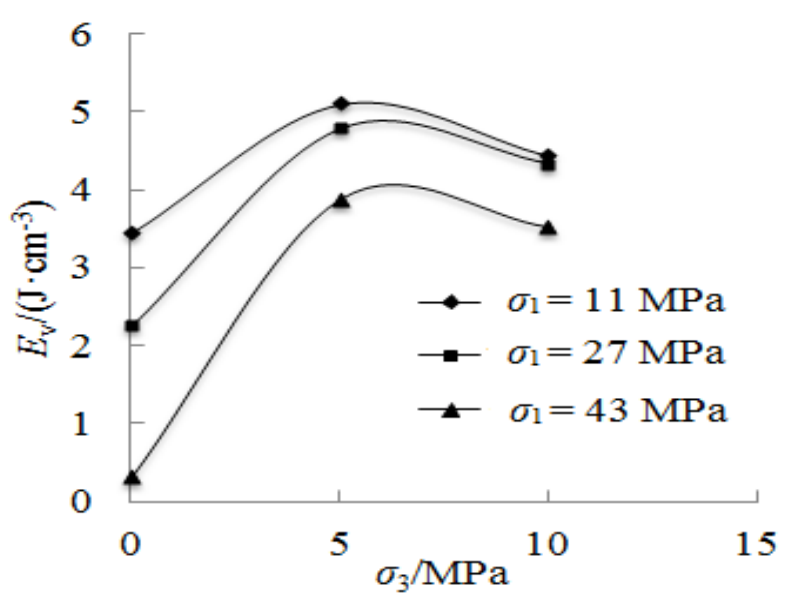

(a)

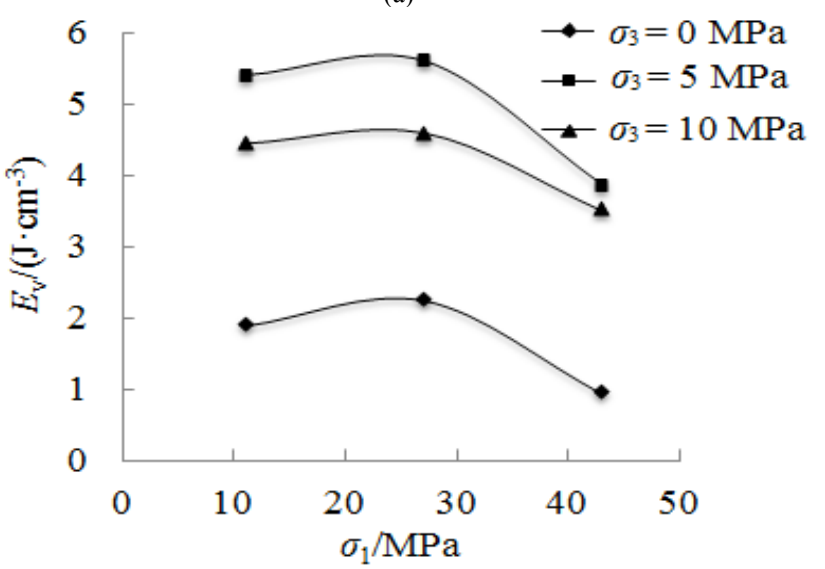

(b)

Fig. 7 Energy transfer mechanisms of red sandstone under 3D coupled static and dynamic loads. (a)Variation in the energy absorbed per unit volume of red sandstone in relation to confining pressure. (b) Variation in the energy absorbed per unit volume of red sandstone in relation to axial compression. Ev-the energy absorption per units 


\subsection{Analysis of failure mode under 3D coupled static and dynamic loads}

Scientifically analyzing the failure process according to the depth of rock and the failure mode of the rock under 3D coupled static-dynamic loading is of significance. Figure 8 shows the failure modes of red sandstone at different strain rates. Figure 8 (a) shows the failure modes of red sandstone under $27 \mathrm{MPa}$ axial pressure and $10 \mathrm{MPa}$ confining pressure at different strain rates. Figure 8(b) shows the failure modes of red sandstone under $43 \mathrm{MPa}$ axial pressure and without confining pressure at different strain rates. Figure 8(c) shows the failure modes of red sandstone under $43 \mathrm{MPa}$ axial pressure and $10 \mathrm{MPa}$ confining pressure at different strain rates. As shown in Fig.8, the damage degree to red sandstone increases with an increase in strain rate, regardless of the axial compression and confining pressure. As shown in Fig.8 (a), the rock sample was hardly destroyed when stressed at a strain rate of $137 \mathrm{~s}^{-1}$. When the strain rate is increased to $208.48 \mathrm{~s}-1$, the rock sample exhibits cracks on the upper and lower surfaces; thus, increasing the damage degree. When the strain rate reaches $248 \mathrm{~s}^{-1}$, fragments begin to appear after the rock sample was hit and the damage degree further increases. Figures $8(\mathrm{a})$ and $8(\mathrm{c})$ reveal that the damage increases with increasing axial compression under a given confining pressure, indicating that axial pressure increases the internal damage to rocks. Figures $8(\mathrm{~b})$ and $8(\mathrm{c})$ show that, under a constant axial pressure, the damage degree is increased compared when the confining pressure is $0 \mathrm{MPa}$. Thus, confining pressure can enhance the compressive strength of the rock.

As shown in Fig. 8 (c), when the strain rates are $226 \mathrm{~s}^{-1}$ and $237 \mathrm{~s}^{-1}$, the interior of the rock sample formed a fracture plane within an approximate cone shape after impact. These results indicate that, under $3 \mathrm{D}$ static and dynamic loads, the damage to red sandstone corresponds to the compressionshear failure mode of the rock.

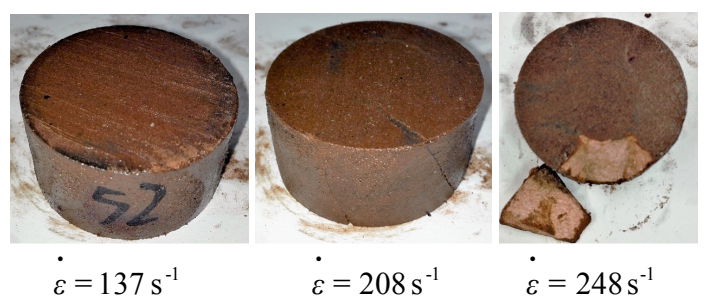

(a)

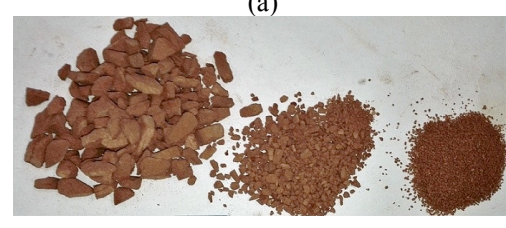

$\varepsilon=142 \mathrm{~s}^{-1}$

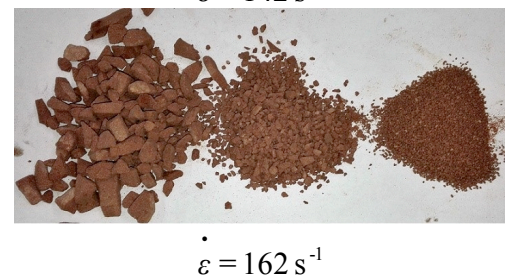

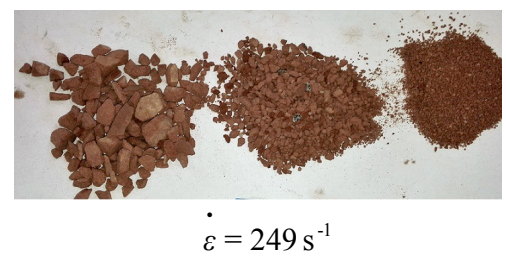

(b)

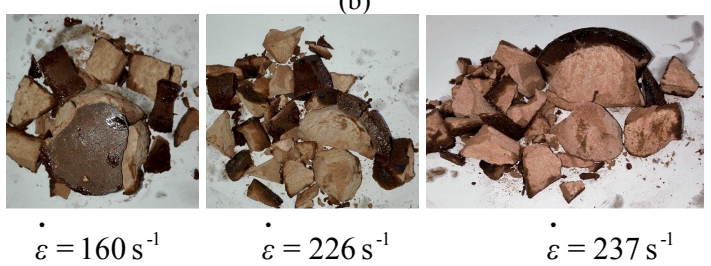

(c)

Fig.8 Failure modes of red sandstone under different strain rates. (a) $\sigma_{1}=27 \mathrm{MPa}, \sigma_{3}=10 \mathrm{MPa}$. (b) $\sigma_{1}=43 \mathrm{MPa}, \sigma_{3}=0 \mathrm{MPa}$. (c) $\sigma_{1}=$ $43 \mathrm{Mpa}, \sigma_{3}=10 \mathrm{MPa}$

\section{Conclusion}

(1) In the three-dimensional coupled static-dynamic loading tests, when the confining pressure is constant, the secant modulus of red sandstone initially increases and subsequently decreases as the axial compression pressure increases, whereas the average strain rate initially decreases and then subsequently increases. When the axial pressure is constant, the secant modulus of the red sandstone initially increases and then decrease as the confining pressure increases, whereas the average strain rate initially decreases and subsequently increases.

(2) When the confining pressure is constant, the overall the compressive strength of red sandstone is initially increased and subsequently decreased with increasing axial pressure, and the maximum compressive strength is reached when the axial pressure ratio is approximately 0.5 . When the axial pressure is constant, the compressive strength increases with the confining pressure.

(3) Under the 3D coupled static-dynamic loading condition, the energy absorbed per unit volume of red sandstone initially increases and subsequently decreases with increases in confining pressure and axial pressure.

(4) Under the 3D coupled static-dynamic loading condition, the damage degree to red sandstone increases with an increase of strain rate. The increase in axial static pressure can increase the damage inside the rock, whereas the confining pressure can improve the compressive strength of the rock. After impact, the red rock achieves shear compression failure modes, showing the cone shape of the rupture surface.

This article focuses on the study of the mechanical properties of red sandstone under different axial pressures and different confining pressures and 3D movement combined loading. The results of this study provide a better explanation of the deviation between the mechanics of deep rock and shallow rocks, as well as a certain theoretical guidance for deep mining.

\section{Acknowledgements}

This paper was supported by the National Science Foundation of China (Grants 41362013, 41202229 and 51304087). 


\section{References}

1. Li Xibing, Zhou Zilong, Lok Tat-Seng, Hong Liang, Yin Tubing, "Innovative testing technique of rock subjected to coupled static and dynamic loads". International Journal of Rock Mechanics and Mining Sciences, 45(5), 2008,pp.739-748.

2. Demirdag, S., Tufekci, K., Kayacan, R., Yavuz, H., Altindag, R., "Dynamic mechanical behavior of some carbonate rocks". International Journal of Rock Mechanics and Mining Sciences, 47(2),2010,pp.307312 .

3. Bailly, P., Delvare, F., Vial, J., Hanus, J.L., Biessy, M., Picart, D., "Dynamic behavior of an aggregate material at simultaneous high pressure and strain rate: SHPB triaxial tests". International Journal of Impact Engineering, 38(2-3), 2011,pp.73-84.

4. Zhang, Q.B., Zhao J., "Effect of loading rate on fracture toughness and failure micromechanisms in marble". Engineering Fracture Mechanics, 102(1), 2013,pp.288-309.

5. Li Xibing, Zuo Yujun, Wang Weihua, Ma Chunde, Zhou Zilong, "Constitutive model of rock under static-dynamic coupling loading and experimental investigation". Transactions of Nonferrous Metals Society of China, 16(3), 2006,pp.714-722.

6. Zhou Zilong, Li Xibing, Ye Zhouyuan, Liu Kewei, "Obtaining Constitutive Relationship for Rate-Dependent Rock in SHPB Tests". Rock Mechanics and Rock Engineering, 43(6), 2010,pp.697-706.

7. Ye Zhouyuan, Zhao Fujun, Zhou Zilong, "Mechanical characteristics of unloading rock under coupled dynamic and static loads". Chinese Journal of Geotechnical Engineering, 35 (3), 2013,pp. 454-459.

8. Ye Zhouyuan, Li Xibing, Liu Xiling, Ma Chunde, Yin Tubing, "Testing studies on rock failure modes of statically loads under dynamic loading". Trans Tianjin University, 14(1), 2008,pp. 530-535.
9. Yin Zhiqiang, Li Xibing, Jin Jiefang, He Xianqun, Du Kun, "Failure characteristics of high stress rock induced by la disturbance under confining pressure unloading". Transaction of Nonferrous Metals Society of China, 22(1), 2012,pp.175-184.

10. Ramulu, M., Chakraborty, A.K., Sitharam, T.G., "Damage assessment of basaltic rock mass due to repeated blasting in a railway tunnelling project-A case study". Tunneling and Underground Space Technology, 24(2), 2009, pp.208-221.

11. Li Haibo, Xia Xiang, Li Jianchun, Zhao Jian, Liu Bo, Liu Yaqun, "Rock damage control in bedrock blasting excavation for a nuclear power plant". International Journal of Rock Mechanics and Mining Sciences, 48(2), 2011,pp.210-218.

12. Jin Jiefang, Li Xibing, Zhong Haibing, "Study of dynamic mechanical characteristic of sandstone subjected to three-dimensional coupled static cyclic impact loadings". Chinese Journal of Rock Mechanics and Engineering, 32(7), 2013, pp.1358-1372.

13. Gong Fengqiang, Li Xibing, Liu Xiling, "Preliminary experimental study of characteristics of rock subjected to 3D coupled static and dynamic loads". Chinese Journal of Rock Mechanics and Engineering, 30(6), 2011, pp.1179-1190.

14. Zhou ,X.P., Wang ,F.H., Qian, Q.H., Zhang B.H., "Zonal fracturing mechanism in deep crack-weakened rock masses". Theoretical and Applied Fracture Mechanics, 50(1), 2008,pp.57-65.

15. Dirk Mohr, Gerard Gary, Bengt Lundberg. "Evaluation of stressstrain curve estimates in dynamic experiments". International Journal of Impact Engineering, 37(2), 2010,pp.161-169.

16. Zhou Y.X., Xia ,K., Li ,X.B., Li ,H.B., Ma, G.W., Zhao J., Zhou Z.L., Dai F., "Suggested methods for determining the dynamic strength parameters and mode-I fracture toughness of rock materials". International Journal of Rock Mechanics and Mining Sciences, 49(1), 2012,pp.105-112. 